\title{
IMR 2018 - Jede Menge Basis- und Spezialwissen
}

Über 250 Radiologinnen und Radiologen folgten am 14. und 15. September der Einladung der DRG-Arbeitsgemeinschaft Bildgebende Verfahren des Bewegungsapparates zum zweiten Intensivkurs Muskuloskelettale Radiologie in Hamburg. Im Helmut Schmidt Auditorium der Bucerius Law School hatten sie wieder die Möglichkeit, ihre Kenntnisse in unterschiedlichen Teilgebieten der muskuloskelettalen Diagnostik aufzufrischen und zu vertiefen.

Im Mittelpunkt standen dabei die Diagnostik von Knochentumoren, die Gelenkdiag- nostik (Ellenbogen, Hüftgelenk und Fuß), putride und non-putride Entzündungen sowie sportassoziierte Verletzungen von Muskeln, Sehnen und Gelenken.

Ein interaktives Ted-Quiz mit prominenter Beteiligung rundete das fachliche Programm ab. Ivica Olić, ehemaliger Fußballnationalspieler Kroatiens mit langjähriger Bundesligaerfahrung (u. a. HSV und Bayern München), übernahm dabei die Rolle der „Glücksfee“ und stand anschließend auch für ein Meet and Greet zur Verfügung.

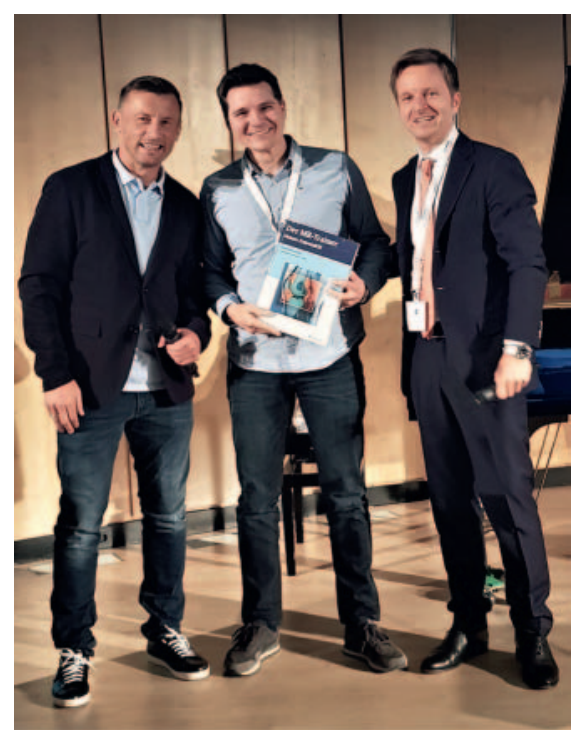

Fußballprofi Ivica Olić (links) und Prof. Dr. Marc Regier (rechts), wissenschaftlicher Leiter des Intensivkurses Muskuloskelettale Radiologie, gratulieren einem der TedQuiz-Gewinner. @ Deutsche Röntgengesellschaft e.V. 